\title{
Classificação psiquiátrica: tensionamento atual entre realismo e nominalismo
}

\section{| ${ }^{1}$ Rogério da Silva Paes Henriques |}

Resumo: Apresenta-se o "nominalismo dinâmico" de Hacking, aplicado à classificação psiquiátrica, como exemplo ilustrativo de síntese entre realismo e nominalismo. Expóem-se as perspectivas realistas inscritas tanto moderadamente na proposta híbrida do Diagnostic and Statistical Manual of Mental Disorders (DSM-5), quanto fortemente na proposta naturalista de seus concorrentes: Research Domain Criteria (RDoC) e Hierarchical Taxonomy of Psychopathology (HiTOP). Aponta-se o principal efeito do naturalismo aplicado à classificação psiquiátrica, que consiste no abandono do hibridismo entre realismo e nominalismo, em prol de uma cartografia do mental que, com recurso à matemática, reivindica-se estritamente realista, respondendo a demanda por maior precisão da bipsiquiatria.

> Palavras-chave: nosografia; DSM-5; RDoC; HiTOP; medicina de precisão.

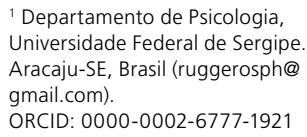

' Departamento de Psicologia, Universidade Federal de Sergipe. Aracaju-SE, Brasil (ruggerosph@ gmail.com).

ORCID: 0000-0002-6777-1921

Recebido em: 04/07/2019 Aprovado em: 25/03/2020 Revisado em: 22/08/2021 
El nominalismo, antes la novedad de unos pocos, hoy abarca a toda la gente; su victoria es tan vasta y fundamental que su nombre es inútil.

Nadie se declara nominalista porque no hay quien sea outra cosa...

Borges (1995, p. 235).

\section{Introdução}

A classificação psiquiátrica incita u ma questão filosófica sobre o estatuto ontológico dos chamados atualmente "transtornos mentais". Em que consistem as categorias ou constructos psicopatológicos descritos nas nosografias ou classificaçôes psiquiátricas contemporâneas? Elas expressam "tipos naturais" (natural kinds) descobertos pelo desenvolvimento das ciências médicas ou "tipos artificiais" (artificial kinds) forjados por esquemas classificatórios articulados à linguagem humana? São classes de objetos que ocorrem naturalmente, propriedades ou processos que são descobertos e existem independentemente do classificador (ex: elétrons, $\mathrm{H}_{2} \mathrm{O}$, peixes) ou são classes convencionais impostas à natureza e inventadas pelos classificadores (ex: triângulo, dinheiro, veículos)? Em outros termos: as categorias psiquiátricas são produzidas pelo mundo ou por nós? Trata-se de uma questão legítima que recebe o aval dentre outros do filósofo Putnam (1990), e que toca direta ou indiretamente aqueles que se ocupam da filosofia da psiquiatria. Tal questão costuma pôr em cena duas perspectivas filosóficas distintas: realismo e nominalismo.

Em linhas gerais, o realismo afirma a "realidade dos universais (gêneros e espécies), entendendo, contudo, de maneiras diferentes essa mesma realidade" (ABBAGNANO, 2007, p. 834). A dimensão ontológica dessa vertente afirma que os entes possuem existência própria, independente da cognição humana (autonomia metafísica), enquanto sua dimensão epistemológica afirma que eles podem ser meticulosamente reconhecidos e classificados corretamente, em um recorte objetivo que "disseque a natureza em suas juntas" (acessibilidade epistêmica) - conforme conhecida metáfora. Em suma, presume-se que o mundo objetivo, que "está lá fora”, exista independentemente da dialética intersubjetiva, podendo ser apreendido fidedignamente. Por sua vez, a tradição metafísica nominalista afirma "que, além das substâncias singulares, só existem os nomes puros e, portanto, eliminam a realidade das coisas abstratas e universais" (Leibniz, citado por ABBAGNANO, 2007, p. 715). Presume-se que os entes nada têm em comum senão os signos linguísticos que os designam como tais. $\mathrm{O}$ que se presume serem universais (entes objetivos predicados 
de todos os demais entes) ou objetos abstratos (não localizados no espaço-tempo e causalmente inertes) sáo, por exemplo, propriedades, números, proposições, mundos possíveis... Aquilo que caracteriza a perspectiva nominalista não é negar tais entidades em si mesmas, mas antes rejeitá-las como universais ou abstratas. Desse modo, o nominalismo é compatível com a aceitação delas, desde que concebidas como particulares ou concretas. ${ }^{1}$

No que tange à psiquiatria, mais especificamente às classificaçóes de doenças nesse campo, na atualidade, tende-se fortemente ao realismo. Apresentaremos um panorama da proposta nominalista de Ian Hacking (1995; 2000; 2002) como contraponto necessário às perspectivas ontológico-realistas inscritas tanto como "projeto fraco" na proposta classificatória do Diagnostic and Statistical Manual of Mental Disorders (DSM), quanto como "projeto forte" na proposta classificatória de seus concorrentes: projeto Research Domain Criteria (RDoC) e consórcio Hierarchical Taxonomy of Psychopathology (HiTOP). Visa-se a estabelecer uma crítica ao realismo naturalista que embasa tais propostas classificatórias, apontando seus efeitos.

\section{Perspectiva "nominalista” de Ian Hacking}

O modelo adotado pela medicina após a revolução bacteriológica, pautado nas doenças infecciosas, do qual um dos emblemas é a tuberculose (TB), propaga a tese realista. No século XIX, a consunção não era doença, mas sim falha moral causada por defeitos de caráter. Com a descoberta dos germes que causavam a consunção, contudo, a explicação oitocentista deu lugar a outra, científica, que a descreveu como uma doença específica transmitida por micróbios. A TB demonstrou assim possuir uma existência própria como entidade patológica, independentemente do modo como havia sido descrita até então. O mesmo ocorreu com a sífilis: suas descrições através da história, os "estilos de pensamento" (FLECK, 1986) que incidiram sobre ela - seja como entidade atrelada ao mal venéreo, seja como entidade empírica reagente ao mercúrio -, não modificaram sua natureza ou essência como doença infecciosa, descoberta com o teste Wassermann. O que os germes causadores da TB e da sífilis fazem não depende, ao menos não de modo direto, da maneira como os descrevemos. Nesses casos, o nominalismo radical malogra, já que ele supóe que todas as categorias, classes e taxonomias são dadas pelos seres humanos, e nunca pela natureza. Ian Hacking assume uma posição nominalista peculiar, afirmando 
que muitas categorias provêm da natureza, e não de nossos esquemas mentais, além do que nossas categorias não são estáticas. Hacking segue então um "nominalismo dinâmico" assim definido: "um tipo (kind) de pessoa vem à existência ao mesmo tempo em que o próprio tipo (kind) foi inventado. Em alguns casos, nossas classes e classificações conspiram para aparecer uma suportada pela outra" (HACKING, 2002, p. 106). Seu nominalismo procura dar conta "de como as classes e os classificados se ajustam e se adequam mutuamente entre si, de como surgem simultaneamente a classe e os membros que a mesma inclui" (MARTINEZ, 2010).

Para exemplificar sua proposta, Hacking (2002) toma quatro categorias: cavalos, planetas, luvas e personalidades múltiplas. ${ }^{2}$ Afirma ser errôneo sugerir, como faz o nominalismo estrito, que a única coisa que os cavalos têm em comum é o nome, isto é, o fato de nós os chamarmos "cavalos". Podemos estabelecer os limites de inclusão ou exclusão dos pôneis Shetland, por exemplo, da classe dos cavalos, mas as similaridades e as diferenças entre as duas classes são objetivas o suficiente, sendo apenas reconhecidas por nós. Da mesma forma, a disposição dos planetas no sistema solar possui uma lógica intrínseca que não depende da forma como nós os agrupamos. O nominalismo estrito é, portanto, ininteligível para cavalos e planetas. Já as luvas, nós as fabricamos. Mesmo que não saibamos o que veio primeiro, se a palavra ou a coisa, ambos se desenvolveram simultaneamente, a ponto de o conceito designador ("luva") se encaixar perfeitamente ao objeto designado (luva). A hipótese de Hacking sobre a "construçáo de pessoas" (making up people) é que, em alguns aspectos, a personalidade múltipla se assemelha mais às luvas que aos cavalos e planetas. O que é, em alguma medida, extensível a outras categorias psiquiátricas atuais. Hacking afirma que não há duas maneiras idênticas de "construir" pessoas, o que torna impossível um método de análise geral. Suas análises são sempre singulares e específicas: "obesos", "homossexuais", "múltiplos" etc. Isso não impede, contudo, a generalização da sua ideia básica: as classificaçôes psiquiátricas mudam as formas de pensar, sentir e agir das pessoas que são classificadas, as quais ressignificam sua história atual e pregressa, assim como suas projeçôes para o futuro, à luz dos novos significantes médicos (efeito de looping). ${ }^{4}$

Uma patologia mental antes de descrever uma espécie natural (natural kind), como talvez seja o caso da TB e da sífilis, "cria performativamente uma nova situação na qual sujeitos se veem inseridos", haja vista que categorias psiquiátricas "são objeto de elaboração reflexiva por parte dos próprios sujeitos que elas visam a descrever”. Nesse 
sentido, as categorias psiquiátricas são reflexivas: “Os objetos que elas descrevem (no caso, os sujeitos que portam sintomas, transtornos, angústias, inibiçóes) apreendem tais categorias, identificam-se a elas e se modificam a partir delas" (SAFATLE, 2017, p. 3-4). Diferentemente de um fenômeno físico (ex: uma pedra não se modifica ao ser descrita pela mecânica newtoniana), fenômenos mentais ao serem descritos pelo saber psiquiátrico modificam o objeto sobre o qual incidem: os sujeitos diagnosticados. "Pois estar doente é, a princípio, assumir uma identidade com forte força performativa" (SAFATLE, 2017, p. 4). O ato de nomeação da doença instaura uma nova realidade: "a maneira com que classificamos pessoas não é uma mera descrição de categorias que existem na natureza, mas uma construção que produz pessoas que, a partir de então, apreenderão reflexivamente tais categorias, produzindo efeitos até então inexistentes" (SAFLATE, 2017, p. 11-12). Como corolário dessa perspectiva, temos que "A doença mental é uma identidade social. [...] Uma patologia mental não descreve uma espécie natural [...] ela cria performativamente uma nova situaçâo na qual os sujeitos se veem inseridos" (SAFATLE, 2017, p. 13). Ian Hacking (apud DELILLE; KIRSCH, 2016) apontou ser a esquizofrenia uma categoria em movimento cujas fronteiras, negociadas em cada cultura específica, vão sendo constantemente redefinidas. Vladimir Safatle (2017) apropria-se do nominalismo dinâmico de Hacking em seu curso Uma genealogia das psicoses, com ênfase específica na esquizofrenia - categoria psiquiátrica das mais "robustas" (no sentido de bem confirmadas), paradigmática das psicoses em geral. Sua hipótese é que sequer a esquizofrenia pode ser considerada um tipo natural, ${ }^{5}$ haja vista sua configuração ser mais atravessada pela "circulação de valores sociais e morais ligados à autonomia, à unidade, ao controle e à coerência da conduta" (p. 7) que por fatos biológicos. Em seu estudo epistemológico sobre a esquizofrenia, Safatle (2017) assinala que, desde seu surgimento até os dias atuais, a definição dessa patologia é tributária da noção de "dissociação da personalidade". Ainda hoje, a esquizofrenia atrela-se a "disfunçôes cognitivas e emocionais" que acometem as faculdades mentais que não se submetem mais à estrutura diretiva das condutas e da personalidade própria a um Eu (p. 77-78); se se a considera uma categoria heterogênea e multiforme, "é certamente porque, desde seu início [com as classificaçôes fundadoras de Emil Kraepelin e Eugen Bleuler], a patologia depende de um conceito de unidade, síntese e coerência cujo fundamento se encontra em um horizonte normativo exterior a fatos clínicos" (p. 37). 


\section{Perspectiva classificatória oficial: o DSM}

O DSM se inscreve na tradição inaugurada por Carl Hempel, filósofo da ciência cujo empirismo lógico representou a mais forte influência sobre os artífices do DSMIII. Hempel (citado por Sadler, 2005) propunha que a classificação psiquiátrica se compusesse a partir de definiçóes operacionais, diagnóstico multiaxial, abordagem descritiva, requerimento de testabilidade e minimização das afirmaçôes "valorativas" (p. 74). O DSM-III incorporou tais proposiçôes, reorientando a classificação psiquiátrica rumo ao viés realista descritivo-biológico.

De fato, pode-se constatar que a classificação psiquiátrica mais influente no mundo contemporâneo, editada pela American Psychiatric Association (APA), adota a perspectiva realista, ao definir o transtorno mental como

[...] uma síndrome caracterizada por perturbaçôes clinicamente significativas na cognição, na regulação emocional ou no comportamento de um indivíduo que reflete uma disfunção nos processos psicológicos, biológicos ou de desenvolvimento subjacentes ao funcionamento mental. (APA, 2014, p. 20; grifo nosso)

Tal definição indica que os transtornos mentais classificados pela quinta edição do Manual Diagnóstico e Estatístico de Transtornos Mentais (DSM-5) seriam tipos naturais, haja vista serem causados por uma disfunção em alguns processos naturais intrínsecos à psicologia, biologia ou desenvolvimento do indivíduo, que nada teriam a ver com mecanismos sociais, tal como se constata no seguimento da definição: "Desvios sociais de comportamento [...] e conflitos que são basicamente referentes ao indivíduo e à sociedade não são transtornos mentais, a menos que o desvio ou conflito seja o resultado de uma disfunção no indivíduo...” (APA, 2014, p. 20). O conceito de transtorno mental do DSM possibilita-nos uma inferência ontológica acerca dele, ao insistir que as bases naturais forneceriam os princípios de individuação daquilo que as categorias psiquiátricas devem descrever. O modelo classificatório do DSM, baseado na tipologia categorial dos transtornos mentais, foi importado das ciências naturais. O padrão ouro dos tipos categoriais naturais são os objetos de maior estabilidade advindos da química (elementos da tabela periódica de Mendeleiev) e da física (partículas elementares quânticas). Declinando desse padrão, mas ainda considerados tipos naturais, encontram-se as espécies biológicas (cavalos, peixes, limóes etc.), objetos de estabilidade relativa, pois sujeitos aos processos evolucionários. A perspectiva realista do DSM crê que o modelo das ciências 
naturais se aplica à psiquiatria. Sua definição de transtorno mental reflete a busca ao tipo categorial natural: descontinuidades presentes na natureza, cuja existência independe de interesses humanos. No que tange ao problema da demarcação dos transtornos mentais (ROSS, 2005), o DSM, com viés realista, busca condiçôes necessárias e suficientes que identifiquem propriedades intrínsecas (essências) pertencentes à categoria transtorno. ${ }^{6}$

Por sua vez, no que tange aos seus objetivos, prevalece uma perspectiva claramente pragmática no DSM-5, em sua preocupação com a "utilidade clínica”, como se pode constatar a partir dos seguintes excertos de sua Introdução (APA, 2014):

A avaliação dos critérios diagnósticos, considerando a organização de cada aspecto do Manual e criando novas características, consideradas de maior utilidade para os clínicos, envolveu muito debate e ponderação. (p. 5)

A edição atual, o DSM-5, avança no objetivo de seus predecessores [...] de proporcionar diretrizes para diagnósticos que podem informar tratamentos e decisões de manejo. (p. 6)

[...] o DSM-5 destina-se principalmente a ser um manual para clínicos, e as revisóes devem ser viáveis para a prática clínica de rotina. (p. 7)

Uma recomendação final da Força-Tarefa [elaborativa do DSM-5] foi, então, feita [...], a de levar em consideração algumas das características de utilidade clínica e de viabilidade das revisóes propostas. (p. 10)

Isso só para citar os trechos mais importantes. Impressiona a alta frequência com que a expressão "utilidade clínica" e similares aparece na Introdução do DSM5. Seguramente, trata-se do objetivo, já presente nas ediçôes anteriores, mas agora escancarado por essa nosografia assim elevada ao estatuto de tratado clínico. Isso traz à tona um dilema, apontado por Sadler (2005): a adoção do pragmatismo como valor prevalente sugere que o pêndulo do DSM vem tendendo mais aos tipos artificiais (derivados da demanda social pela práxis terapêutica) que aos tipos naturais para as classificaçóes psiquiátricas (p. 70). Como veremos, as perspectivas críticas ao DSM incidem exatamente sobre esse ponto, impondo o naturalismo sobre tal artificialismo.

Temos que, ao mesmo tempo em que se mostra realista na definição de transtorno mental, o DSM-5 tende à perspectiva nominalista na adoção do pragmatismo ${ }^{7}$ como seu valor prevalente, atrelado à sua eficácia instrumental. A nosso ver, esse hibridismo não constitui um problema em si, haja vista a complexidade do campo do mental exigir a coexistência de perspectivas ontológicas e epistemológicas diversas em sua composição - como o nominalismo dinâmico de Hacking, exposto acima, propóe. 
Contudo, é justamente essa relação estabelecida entre o nominalismo e o realismo, fundada sobre o "utilitarismo social" (entendido aqui como resposta à demanda terapêutica), que vem sendo amplamente questionada no campo das classificaçóes psiquiátricas pelos atuais projetos concorrentes ao DSM.

\section{Perspectivas críticas ao DSM: RDoC e HiTOP Research Domain Criteria (RDoC)}

O projeto "Critérios de domínio da pesquisa" (RDoC) resulta de uma dessas críticas. Coordenado pelo NIHM, o Instituto Nacional de Saúde Mental dos Estados Unidos, o RDoC representa o primeiro passo desse instituto com vistas à promoção de descobertas em ciências cerebrais e comportamentais que fomentem pesquisas sobre as causas dos transtornos mentais; tal projeto objetiva desenvolver, para propósitos de pesquisa, novos modos de classificar transtornos mentais baseados em dimensões do comportamento observável e medidas neurobiológicas (FAUCHER; GOYER, 2015, p. 205). Consiste, segundo Tabb (2017), em criar novos protocolos para a pesquisa classificatória em psiquiatria, independentemente do DSM, com base nos domínios de certas dimensóes fundamentais do funcionamento mental (sobretudo cognitivo) segundo certas unidades de análise. "Este sistema adota um esquema totalmente dimensional e translacional de transtornos mentais, ou seja, ele concebe a psicopatologia em termos de desvios em sistemas funcionais fundamentais" (HENGARTNER; LEHMANN, 2017, p. 2). Em vez da abordagem de cima para baixo do DSM, que primeiro descreve as categorias sindrômicas para depois investigar sua etiopatologia subjacente, o RDoC propóe uma abordagem de baixo para cima, dissolvendo as categorias psiquiátricas em fenômenos dimensionais humanos. Em vez de tipos naturais de doenças, propóem-se espelhar a própria natureza humana, captada em suas cinco dimensóes básicas: "cognição, sistemas de valência negativa, sistemas de valência positiva, sistemas para processamento social e sistemas de regulação/vigilância" (MAIA; CAMPOS, 2017, p. 38). A matriz RDoC encontra-se em Morris e Cuthbert (2012, p. 31), tendo sido traduzida para a língua portuguesa por Maia e Campos (2017, p. 38-39).

Trata-se de projeto de ontologia realista, com ênfase na genética, ciências comportamentais e neurociências, cujos propósitos incluem mapear o conectoma humano - acessando os circuitos neurais subjacentes às funções mentais que orientam o comportamento normal. Esses circuitos neurais funcionalmente definidos são os 
eixos em torno dos quais a neurociência organiza pesquisas (FAUCHER; GOYER, 2015, p. 206). Nesse quesito, o RDoC aproxima-se da "Iniciativa Medicina de Precisão" (National Research Council of National Academies - NRC), mais ligado à medicina genômica, na medida em que ambos procuram pluralizar os objetos diagnósticos via detecção de biomarcadores variados (Insel, 2014).

\section{Hierarchical Taxonomy of Psychopathology (HiTOP)}

Projeto afim ao RDoC é a "Taxonomia Hierárquica da Psicopatologia” (HiTOP), de viés psicopatológico quantitativo. Ambos se complementam mais do que concorrem entre si, tal como sugerido no artigo que apresenta o projeto HiTOP (KOTOV et al., 2017, p. 459). Trata-se de um consórcio de pesquisadores independentes - o referido artigo é composto por quarenta autores predominantemente atuantes nos Estados Unidos -, resultante da insatisfação de longa data com os sistemas classificatórios vigentes e sua inabilidade em modelar adequadamente a estrutura da psicopatologia. "A avaliação no sistema HiTOP enfoca os comportamentos mal adaptativos, que são representados como um continuum variando do normal ao gravemente patológico" (TABB, 2017, p. 8). Possui como objetivo principal "fornecer uma psicopatologia de organização totalmente dimensional baseada empiricamente, submetendo os diagnósticos, síndromes e sintomas atuais a procedimentos fator-analíticos multivariados" (HENGARTNER; LEHMANN, 2017, p. 2). Empenha-se assim em erigir uma estrutura hierárquica quantitativa à psicopatologia, cujo espectro encontra-se em Kotov et. al (2017, p. 462).

Uma inovação pioneira do HiTOP é a incorporação de traços de personalidade à estrutura da psicopatologia (HENGARTNER; LEHMANN, 2017, p. 2). Esse consórcio também se alinha à medicina de precisão, "uma vez que pretende reestruturar a população de pacientes usando novos instrumentos e técnicas, a fim de melhorar a pesquisa psicopatológica e, em última instância, as práticas de tratamento"8 (TABB, 2017, p. 8).

\section{O problema da validação diagnóstica}

$\mathrm{O} \mathrm{RDoC}$ e o HiTOP realizam movimento rumo à validação diagnóstica, calcanhar de Aquiles do DSM, ${ }^{9}$ possuindo interfaces em comum. Nesse sentido, um dos idealizadores do RDoC - Thomas Insel, ex-chefe do NIHM - defende uma "psiquiatria de precisão" definida como "neurociência clínica aplicada" (INSEL; 
QUIRION, 2005). Por sua vez, a classificação quantitativa do HiTOP aventa "efetivamente resumir informaçoos sobre vulnerabilidades genéticas compartilhadas, fatores de risco ambientais, anormalidades neurobiológicas, evolução da doença, comprometimento funcional e eficácia do tratamento" (TABB, 2017, p. 8). Contra os modelos tipológicos, ambos defendem abordagens dimensionais que dispensam a nosologia psiquiátrica tradicional: "em vez de simplesmente contestar a posição operacionalista explícita e o essencialismo implícito do DSM", rejeita-se "o papel central que as categorias diagnósticas desempenharam na definição dos objetivos de validação" (TABB, 2017, p. 11). Abraça-se então uma causa em prol do reconhecimento da pluralidade dos objetos psiquiátricos (que não se reduzem aos tipos categoriais) e do esforço em integrá-los sem a mediação da nosologia oficial, por intermédio da big science. Uma diferença ressaltante entre o RDoC e o HiTOP é que, enquanto este último pretende reformular os procedimentos diagnósticos, aquele se apresenta como braço científico facilitador de futuras revisóes nosológicas em psiquiatria (TABB, 2017, p. 8).

Se a revolução nosológica promovida pelo DSM-III em 1980 e mantida até hoje, com sua abordagem de viés assumidamente neokraepeliniano, ${ }^{10}$ matou Freud e certa recepção estadunidense da psicanálise, via Meyer, que orientou suas duas versôes anteriores, resta ainda o golpe de misericórdia em Kraepelin deixando cair junto com ele qualquer resquício conceitual da psicopatologia clássica que insiste em orientar o DSM-5. Afinal, não se quer repetir o "erro" de Ptolomeu, ${ }^{11}$ isto é, não se quer aderir ao "dogma" nominalista, que afirma ser a linguagem uma imprescindível ferramenta de acesso à verdade. $\mathrm{O}$ realismo naturalista aplicado à classificação psiquiátrica pretende chegar diretamente à "verdade" (tipos naturais), prescindindo da linguagem - eis sua principal diferença com relação ao realismo como vertente histórico-filosófica. O discurso científico visa assim a se tornar uma espécie de metalinguagem, por meio da qual a biopsiquiatria contemporânea, adepta do "fim da história", propóe-se a dar a palavra final, transcendendo as querelas ontológico-epistemológicas e abortando assim as polifonias narrativas gestadas pela psicopatologia, em prol de sua "última versão" irredutivelmente biológica.

Cabe salientar que a perspectiva biológica também orientava as duas primeiras ediçôes do DSM, cujas categorias diagnósticas refletiam diferentes abordagens teóricas ligadas à psicanálise (distinção estrutural entre neurose e psicose), à biologia (síndromes orgânico-cerebrais) e à psicologia (síndromes funcionais). De modo que 
o que houve foi um claro favorecimento pelos artífices do DSM, desde a terceira edição, da biologia em detrimento da psicanálise e da psicologia. Não obstante tal favorecimento, a crítica assinala que o DSM não é explicita nem suficientemente biológico, insistindo no ateoricismo descritivista como metodologia; a classificação psiquiátrica só pode se tornar científica se amalgamando com a biologia.

O cerne da crítica parece residir no fato de que as categorias do DSM, em grande parte herdeiras da psicopatologia clássica (Freud, Kraepelin, Jaspers...), pressupóem validação clínica, baseada em sua eficácia instrumental, mas não validação biológica (etiopatogênica). Não à toa, o DSM-5 ressaltou sua "utilidade clínica" com o intuito de justificar instrumentalmente sua adesão ao "naturalismo da doença" (SADLER, 2005, p. 92), definindo suas categorias segundo o modelo médico sindrômico (sydenhamiano-kraepeliniano). A crítica visa então a denunciar a reificação dessas categorias do DSM em sua "prisão epistêmica" (HYMAN, 2010), onde "forças centrífugas anticientíficas” impedem o progresso científico (LILIENFELD, 2014b). Assim, sugere a crítica, a promíscua relação entre o nominalismo e o realismo, fundada sobre o pragmatismo, na apreensão das categorias psiquiátricas denotaria o esgotamento do modelo do DSM, que deve impreterivelmente ser ultrapassado em prol de uma maior precisão científica, isso para o "bem" dos pacientes psiquiátricos que merecem algo melhor que as bricolagens terapêuticas atuais. Para tanto, é necessário como primeiro passo abandonar definitivamente os tipos artificiais do DSM em favor dos tipos naturais a serem ainda desvelados.

Assim, como empreitada científica, o DSM teria malogrado ao desvelar aquilo que deveria ter sido mantido velado: sua lógica classificatória, em alguma medida, aberta ao efeito performativo da linguagem, que cria categorias de doenças a partir do ato de nomeação (IANNINI; TEIXEIRA, 2014). À sua revelia, o DSM revelou a "impostura" (ao menos, segundo os parâmetros do realismo naturalista) que o sustenta: seus catálogos classificatórios são sempre provisórios, estando parcialmente abertos à negociação pública. Um exemplo ilustrativo ocorreu no famoso episódio da votação interna à APA, que resolveu o dissenso em torno da homossexualidade, julgada naquela ocasiáo anacrônica ao repaginado DSM-III: a mão levantada dos filiados à APA, isto é, o consenso entre os pares, serviu como "garantia científica" à retirada da homossexualidade desse manual. Outrora uma referência hegemônica, essa pseudodemocracia científica ruma para seu fim com as propostas classificatórias concorrentes ao DSM. 


\section{Efeitos do realismo naturalista aplicado à classificação psiquiátrica}

Tanto o RDoC quanto o HiTOP alinham-se à medicina de precisão, que surge na virada do terceiro milênio, com o apogeu dos regimes neoliberais de gestão política, no contexto da eficácia sanitária atrelada à lógica gerencial e à organização do trabalho médico "pós-clínica", caracterizado pela parametrização de procedimentos diagnósticos e terapêuticos; como consequência, dáse o pareamento clínico-metodológico da prática médica ao paradigma epidemiológico-estatístico. Tal racionalidade médica pretende que sua posição seja verdadeira repousando genealogicamente sobre a noção de "evidência científica”, cujo cerne consiste em considerar apenas os saberes referidos a objetos perfeitamente delimitados (reducionismo), a materiais (positivismo) permanentes e não contraditórios (formalismo).

Contudo, recentemente, constata-se um movimento na medicina de precisão que consiste em ir para além da evidência e da estatística, já que estas não mais satisfazem, erigindo a matemática, via big data, como novo credo científico. Nesse sentido, o atual diretor do NIHM, Joshua Gordon (apud TROADEC, 2017) concebe, à moda do pitagorismo, que a matemática é o alfabeto por meio do qual o universo foi escrito. Ele incentiva, portanto, que pesquisadores em neurociências sejam treinados em matemática para que, no futuro, todo experimentador seja também um teórico. Acredita que a matemática pode ter impacto, num curto prazo, em psiquiatria na predição das respostas individuais aos medicamentos e no aprimoramento da medicina de precisão. A presumida matematização do mundo requer uma nova abordagem metodológica em sua decifração que prescinde da linguagem: no lugar das palavras que descrevem tipos artificiais, cifras que desvelam a natureza (tipos naturais) tal como ela é, de modo a não haver mais disjunção entre as palavras e as coisas.

Bem ou mal, o DSM-III inaugurou um esforço de nomeação e de invenção de uma nova língua psiquiátrica, cuja taxonomia não cessa de não se escrever, ${ }^{12}$ ao nomear e renomear transtornos em fluxo contínuo. É tal esforço linguístico que deve ser minado, segundo as pretensões de Gordon, cujo desejo é higienizar o campo que não cessa de nomear e de produzir estatísticas inúteis aos tratamentos psiquiátricos. É preciso, mais que nunca, promover a conjunção entre biologia e matemática, essas duas metades ainda separadas de uma mesma esfera perfeita. Dessa perspectiva, 
não há saída possível senão nos circuitos neuronais decodificados via análises multifatoriais, a compor os "critérios de domínio". Novos modelos matemáticos vêm então disputar com o modelo estatístico sua legitimidade, e a abordagem do $\mathrm{RDoC}$ reivindica ser guiada por dados (data-driven approach). Dados esses cuja escala astronômica (big data) advém de todos os saberes (da biologia molecular ao comportamento) sobre a modelização do funcionamento cerebral, e cuja integração requer imprescindivelmente alto nível de rigor matemático.

Troadec (2017) aponta o principal efeito extraído do aprimoramento da medicina de precisão, passando da evidência materializada no corpo aos dados projetados no ciberespaço. No lugar do "paciente médio", definido estatisticamente, que até então orientou a medicina clássica, surge uma nova figura antropológica a orientar a medicina personalizada do futuro: o "meta-sujeito" que regurgita os gigabytes dos meta-dados recolhidos. Resta saber se os especialistas abandonarão de fato o DSM, cuja obsolescência vem sendo destacada pelo NIHM, ${ }^{13}$ e, com ele, o hibridismo entre realismo e nominalismo, em prol da demanda por precisão, invocadora da ficção utópica de uma cartografia do mental que não se reduz à nomeação e que se entroniza no realismo científico naturalista.

\section{Referências}

ABBAGNANO, N. Dicionário de filosofia. Sáo Paulo: Martins Fontes, 2007.

AMERICAN PSYCHIATRIC ASSOCIATION. Manual Diagnóstico e Estatístico de Transtornos Mentais: DSM-5 (2013). Porto Alegre: Artmed, 2014.

BORGES, J. L. Otras inquisiciones. Madrid: Alianza, 1995.

DECKER, H. S. How Kraepelinian was Kraepelin? How Kraepelinian are the neoKraepelinians? - from Emil Kraepelin to DSM-III. History of Psychiatry, v. 18, n. 3, p. 337-360, 2007. doi: 10.1177/0957154X07078976. Acesso em: 23/07/2018.

DELILLE, E.; KIRSCH, M. Natural or Interactive Kinds? Les maladies mentales transitoires dans les cours de Ian Hacking au Collège de France (2000-2006). Revue de synthèse, v. 137, n. 6, p. 87-115, 2016. doi: 10.1007/s11873-016-0298-2. Acesso em: 23/07/2018.

FAUCHER, L.; GOYER, S. RDoC: Thinking Outside the DSM Box Without Falling into a Reducionist Trap. In: DEMAZEUX, S.; SINGY, P. (Eds.) The DSM-5 in Perspective. Philosophical Reflections on the Psychiatric Babel. New York: Springer, 2015, p. 199-224.

FLECK L. La génesis y el desarollo de un hecho científico. Madrid: Alianza Editorial, 1986. 
FRANCES, A. RDoC is necessary, but very oversold. World Psychiatry, v. 13, n. 1, p. 47-49, 2014. doi: 10.1002/wps.20102. Acesso em: 22/07/2018.

FRANCES, A. Voltando ao normal: como o excesso de diagnósticos e a medicalização da vida estão acabando com a nossa sanidade e o que pode ser feito para retomarmos o controle. Rio de Janeiro: Versal, 2016.

HACKING, I. The looping effects of human kinds. In: SPERBER, D.; PREMACK, D.; PREMACK, A. J. (Eds.) Causal Cognition: A Multidisciplinary Debate. Oxford: Clarendon Press, 1995, p. 351-383.

HACKING, I. Múltipla personalidade e as ciências da memória. Rio de Janeiro: José Olympio, 2000.

HACKING, I. Making Up People. In: Historical Ontology. Cambridge: Harvard University Press, 2002, p. 99-114.

HENGARTNER, M. P.; LEHMANN, S. N. Why psychiatric Research Must Abandon Traditional Diagnostic Classification and Adopt a Fully Dimensional Scope: Two Solutions to a Persistent Problem. Frontiers in Psychiatry, v. 8, p. 1-5, 2017. doi: 10.3389/fpsyt.2017.00101. Acesso em: 22/07/2018.

HYMAN, S. E. The diagnosis of mental disorders: the problem of reification. Annu Rev Clin Psychol, v. 6, p. 155-179, 2010. doi:10.1146/annurev.clinpsy.3.022806.091532. Acesso em: 23/07/2018.

IANNINI, G.; TEIXEIRA, A. Reflexóes sobre o DSM-100. Opção Lacaniana, ano 5, n. 14, 2014. Disponível em: <http://www.opcaolacaniana.com.br/pdf/numero_14/Reflexoes_ sobre_o_DSM_100.pdf >. Acesso em: 21/05/2015.

INSEL, T. The NIMH research domain criteria (RDoC) project: Precision medicine for psychiatry. American Journal of Psychiatry, v. 171, n. 4, p. 395-397, 2014. doi: 10.1176/appi. ajp.2014.14020138. Acesso em: 22/07/2018.

INSEL, T.; QUIRION, R. Psychiatry as a clinical neuroscience discipline. JAMA, v. 294, n. 17, p. 2221-2224, 2005. doi: 10.1001/jama.294.17.2221. Acesso em: 23/07/2018.

KINCALD, H.; SULLIVAN, J. (ed.) Classifying psychopathology: mental kinds and natural kinds. Cambridge: MIT Press, 2014.

KLERMAN, G. The evolution of a scientific nosology. In: Shershow, J. C. (Ed.) Schizophrenia: Science and Practice. Cambridge: Harvard University Press, 1978, p. 99-121.

KOTOV, R.; KRUEGER, R. F.; WATSON, D.; ACHENBACH, T. M.; ALTHOFF, R. R.; BAGBY, R. M. et al. The hierarchical taxonomy of psychopathology (HiTOP): a dimensional alternative to traditional nosologies. J Abnorm Psychol, v. 126, n. 4, p. 454-477, 2017. doi: 10.1037/abn0000258. Acesso em: 22/07/2018. 
LACAN, J. O seminário, livro 20: mais, ainda (1972-1973). Rio de Janeiro: Jorge Zahar, 2008. LILIENFELD, S. O. The research domain criteria (RDoC): an analysis of meth-odological and conceptual challenges. Behav Res Ther, v. 62, p. 129-39, 2014a. doi:10.1016/j.brat.2014.07.019. Acesso em: 22/07/2018.

LILIENFELD, S. O. DSM-5: centripetal scientific and centrifugal antiscientific forces. Clin Psychol Sci Pract, v. 21, p. 269-79, 2014b. doi:10.1111/Cpsp.12075. Acesso em: 22/07/2018.

MAIA, C. A.; CAMPOS, E. M. Estado da arte da nosologia psiquiátrica: RDoC em debate. Rev Med UFC, v. 57, n. 1, p. 36-42, 2017. doi: 10.20513/2447-6595.2017v57n1p36-42. Acesso em: 23/07/2018.

MARTÍNEZ, M. L. Ontología histórica y nominalismo dinámico: La propuesta de Ian Hacking para las ciencias humanas. Cinta moebio, v. 39, p. 130-141, 2010. Disponível em: https://revistas.uchile.cl/index.php/CDM/article/view/11065/11323. Acesso em: 24/05/2018.

MILLER, A. Realism. The Stanford Encyclopedia of Philosophy (Winter 2016 Edition), Edward N. Zalta (Ed.). Disponível em: https://plato.stanford.edu/archives/win2016/entries/realism/. Acesso em: 24/05/2018.

MORRIS, S. E.; CUTHBERT, B. N. Research Domain Criteria: cognitive systems, neural circuits, and dimensions of behavior. Dialogues in Clinical Neuroscience, v. 14, n.1, p. 2937, 2012. Disponível em: https://www.ncbi.nlm.nih.gov/pmc/articles/PMC3341647/pdf/ DialoguesClinNeurosci-14-29.pdf. Acesso em: 24/07/2018.

MURPHY, D. "Deviant Deviance": Cultural Diversity in DSM-5. In: DEMAZEUX, S.; SINGY, P. (Eds.) The DSM-5 in Perspective. Philosophical Reflections on the Psychiatric Babel. New York: Springer, 2015, p. 97-110.

PUTNAM, H. Realism with a Human Face. Cambridge: Harvard University Press, 1990.

RODRIGUEZ-PEREYRA, G. Nominalism. In: Metaphysics. The Stanford Encyclopedia of Philosophy (Winter 2016 Edition), Edward N. Zalta (Ed.). Disponível em: https://plato.stanford. edu/archives/win2016/entries/nominalism-metaphysics/. Acesso em: 24/05/2018.

ROSS, P. Sorting Out The Concept Disorder. Theoretical Medicine and Bioethics, v. 26, n. 2, p. 115-140, 2005. doi: 10.1007/s11017-005-7946-0. Acesso em: 23/07/2018.

SAFATLE, V. Uma genealogia das psicoses. Curso ministrado no Instituto de Psicologia da Universidade de São Paulo. 2017. Disponível em: https://www.academia.edu/33816445/Curso_ integral_-_Uma_genealogia_das_psicoses_2017_. Acesso em: 16/05/2018.

SADLER, J. Z. Values and psychiatric diagnosis. New York: Oxford University Press, 2005.

TABB, K. Philosophy of psychiatry after diagnostic kinds. Synthese, 2017. Disponível em: https://doi.org/10.1007/s11229-017-1659-6. Acesso em: 25/05/2018. 
TROADEK, J-C. Le DSM se meurt, longue vie au RDoC! Lacan Quotidien, n. 727, 2017. Disponível em: http://www.lacanquotidien.fr/blog/wp-content/uploads/2017/06/LQ-727-D. pdf. Acesso em: 12/01/2020.

TSOU, J. Depression and suicide are natural kinds: Implications for physician-assisted suicide. International Journal of Law and Psychiatry, v. 36, p. 461-470, 2013. doi: 10.1016/j. ijlp.2013.06.013. Acesso em: 16/05/2018.

TSOU, J. DSM-5 and Psychiatry's Second Revolution: Descriptive vs. Theoretical Approaches to Psychiatric Classification. In: DEMAZEUX, S.; SINGY, P. (Eds.) The DSM-5 in Perspective. Philosophical Reflections on the Psychiatric Babel. New York: Springer, 2015, p. 43-62.

TSOU, J. Natural kinds, psychiatric classification and history of the DSM. History of Psychiatry, v. 27, n. 4, p. 406-424, 2016. Disponível em: https://doi.org/10.1177/0957154X16656580. Acesso em 25/05/2018. Acesso em: 16/05/2018.

WEINBERGER, D. R.; GLICK, I. D.; KLEIN, D. F. Whither research domain criteria (RDoC)? The good, the bad, and the ugly. JAMA Psychiatry, v. 72, n.12, p. 1161-1162, 2015. doi:10.1001/jamapsychiatry.2015.1743. Acesso em: 23/07/2018.

ZACHAR, P; STOYANOV, D. St; ARAGONA, M.; JABLENSKY, A. (Eds.). Alternative perspectives on psychiatric validation. New York: Oxford University Press, 2015.

\section{Notas}

${ }^{1}$ Para mais informaçôes sobre o realismo e nominalismo, ver, respectivamente, Miller (2016) e Rodriguez-Pereyra (2016).

${ }^{2}$ Encontra-se uma discussão filosófica detalhada dessa anacrônica categoria diagnóstica em Hacking (2000). Frances (2016, p. 162-165) a discute como um modismo psiquiátrico do passado, aquilo que Hacking (citado por Delille \& Kirsch, 2016) designa por “transtorno mental transitório", quando uma dada condição assume uma forma endêmica e, depois, desaparece. Por sua vez, Murphy (2015, p. 108) sugere que a introdução, no DSM-5, da experiência de possessão (similar à personalidade múltipla) ao transtorno dissociativo de identidade (TDI) seria indicativo de uma tendência humana básica a tal experiência; cabe esclarecer que a possessão, descrita até então como fenômeno cultural específico, foi incorporada ao TDI como fato global da experiência humana, associada à "Ruptura da identidade caracterizada pela presença de dois ou mais estados de personalidade distintos, descrita em algumas culturas como uma experiência de possessão" (APA, 2014, p. 292).

${ }^{3}$ De inspiração foucaultiana, esse tipo de dispositivo envolve agenciamentos não só entre classes e sujeitos classificados, incluindo também no mínimo: instituições, conhecimento/saber e especialistas.

${ }^{4}$ Looping pode ser traduzido literalmente como "amarração", "enlaçamento" etc. Optamos por deixar a expressão inglesa em sua forma original denotando uma relação de mútua implicação entre o sujeito e o Outro social. Curioso que ao tratar dessa mesma relação, com enfoque na estrutura do sujeito, o psicanalista Jacques Lacan invoque a fita de Moebius, que não é sem relação com o looping ("double boucle" lacaniano) tomado como espaço topológico. 
${ }^{5}$ Diferentemente dos objetos de maior estabilidade (elementos químicos, partículas físicas elementares, espécies biológicas), no campo das ciências humanas - deduz-se de Hacking (1995) -, os objetos descritos (ex.: tipos de pessoas) sofrem os efeitos de retroalimentação social (efeito de looping) e, portanto, são inerentemente instáveis, variando em função dos significantes utilizados nas suas descriçôes. Por sua vez, os objetos da psiquiatria aproximar-se-iam mais às ciências humanas que às ciências naturais.

" O "transtorno" do DSM equivale ao "táxon" de Hempel, "definido pela especificação de condiçôes necessárias e suficientes dos membros dela, isto é, pelo estabelecimento de certas características que todos e apenas os membros dessa classe possuem" (citado por SADLER, 2005, p. 65).

${ }^{7}$ Utiliza-se o termo pragmatismo no sentido de John Dewey (citado por ABBAGNANO, 2007, p. 784), como exigência do caráter instrumental e operacional de todos os procedimentos do conhecer, num óbvio parentesco com a metodologia científica contemporânea.

${ }^{8}$ Esforços analítico-críticos dessas propostas vêm sendo empreendidos com êxito, aos quais remetemos os leitores interessados, tendo em vista o limite de espaço do presente artigo. Destaque a Sadler (2005, p. 291-326), que analisa a nosologia genética de uma perspectiva valorativa - extensível à medicina de precisão. Para abordagens críticas do RDoC, destaque a Zachar, Stoyanov, Aragona e Jablensky (2015); ver também Lilienfeld (2014a); Weinberger, Glick e Klein (2015). Sobre o HiTOP, ver Kotov et al. (2017); Tabb (2017); Hengartner e Lehmann (2017).

${ }^{9}$ A nova metodologia adotada a partir do DSM-III, que respondeu à demanda por maior cientificidade, avançou no que tange à "confiabilidade" (reliability) das categorias psiquiátricas, isto é, à sua reprodutibilidade - graças à adoção do "índice Kappa”, elaborado por Fleiss, que é uma medida estatística indicativa do grau de concordância entre diagnósticos orientados pelo DSM comparados a uma classificaçáo que fosse feita ao acaso. Contudo, sua "validação" (validity), ou seja, sua exatidão ou precisão, bem como sua "projeção" (projectability), quer dizer, sua predição prognóstica, permanecem muito insatisfatórios.

${ }^{10}$ Ver o manifesto em prol do movimento neokraepeliniano apresentado por Klerman (1978), um dos mais influentes psiquiatras biológicos dos Estados Unidos. Sobre a apropriação de Kraepelin pelos neokraepelinianos, ver Decker (2007).

${ }^{11}$ Ptolomeu (século II) defendeu a teoria geocêntrica, que perdurou até o século XVI, devido à sua aderência ao pensamento dogmático de Aristóteles. A física aristotélica distinguia o movimento de seres supralunares, sempre perfeito e circular, do movimento de seres sublunares, que sobem ou descem. Sendo a Terra um corpo sublunar e aparentemente imóvel - pois caso houvesse movimento, estes seriam irregulares e percebidos por aqueles que nela habitam -, deduz-se que a Terra é o centro ao redor do qual giram o Sol e os demais astros. ${ }^{12}$ Jacques Lacan (2008), apropriando-se das lógicas moderna e aristotélica, define a modalidade do "impossível" como "o que não cessa de não se escrever". Essa definiçẫo foi utilizada aqui para demarcar que, diante do impossivel, o DSM náo se mostrou impotente, como parece ser o caso, talvez, de seus concorrentes.

${ }^{13}$ Um autor como Jonathan Tsou (2013; 2015; 2016), por exemplo, na contramão do NIHM, apresenta seu projeto de validação das classificações psiquiátricas em conciliação com a abordagem descritiva e ateórica do DSM. Trata-se de proposta continuísta ao DSM. Ele sugere assim um "projeto fraco" que objetiva, em última instância, à passagem do nível da descrição dos tipos naturais à prescrição clínica. Para tanto, sugere acrescentar informaçôes relativas às "bases naturais claras" (entendidas como hipóteses etiológico-biológicas) às categorias descritivas do DSM. Por sua vez, Frances (2014) alega que a psiquiatria descritiva do DSM e CID (Classificação Internacional de Doenças) é atualmente a única que pode efetivamente auxiliar os pacientes psiquiátricos, não os negligenciando no presente em nome de um futuro utópico, conforme a promessa do NIHM. 


\section{Abstract}

\section{Management of diabetes by professionals and users of Primary Health Care}

Diabetes is a disease that cannot be cured, but managed, and its management is seen as a strategy to overcome its unpleasant consequences in various life situations. This study aims to understand how the diabetes mellitus 2 management process occurs by professionals and users affected by this condition. This is a qualitative research, with observational and explanatory design, which included the participation of health professionals and users they care for, all from primary health care. Information was collected through semi-structured interviews and interpreted using Discourse Analysis. For informants, food aspects are the most difficult to deal with. The professionals' discourse points to flexible eating practices, but users understand the guidelines as prohibitions. Feeding represents a great challenge for both professionals and users, as both need to consider management practices as part of care.

Keywords: diabetes mellitus; patient's compliance; health knowledge; attitudes; practice. 